\title{
Optimization of insoluble dietary fiber preparation technology from rosa roxburghii pomace by chemical method
}

\author{
ZHOU Xiao-li ${ }^{a}$, YANG Yan-sheng, YANG Qiao-mei, GUAN Qing-lin, ZHU Guang-xu \\ College of Food and Pharmacy Engineering, Guiyang University, Guiyang, Guizhou 550005
}

\begin{abstract}
Rosa roxburghii residue as raw material, we studied the extraction process of dietary fiber from rosa roxburghii pomace by chemical method. The effects of temperature, time, $\mathrm{pH}$, solid-liquid ratio on the IDF yield under the effect of alkali and acid were explored by single factor experiments and orthogonal experiment. The results showed that the optimal condition of extracting IDF was as follows: the 60 mesh rosa roxburghii pomace were $80 \mathrm{~min}$ in water bath at $60^{\circ} \mathrm{C}$ under the condition of the solid-liquid ratio 1:15 and the $\mathrm{pH} 12$; and then rosa roxburghii pomace were $100 \mathrm{~min}$ in water bath at $50^{\circ} \mathrm{C}$ on the condition of the solid-liquid ratio $1: 15$, and $\mathrm{pH} 3.0$ after rinsing, the average IDF yield which reached $(86.3 \pm 1.0) \%$. This experiment provides experimental basis for the selection of dietary fiber raw materials, and also provides theoretical basis for increasing the added value of rosa roxburghii.
\end{abstract}

\section{Introduction}

With the rapid development of science and technology, the living standard has been improved significantly, which has also resulted in the increasing incidence of human "civilization disease". As dietary fiber has the function of preventing obesity and diabetes, it has been paid more and more attention, and its development and utilization has been generally recognized [1-3]. Although the research and development of dietary fiber started late in China, the sources of materials used in the production of dietary fiber in China are very wide. Various byproducts of food processing can be developed and utilized in a large number, among which insoluble dietary fiber (IDF) is not digested and absorbed by human endogenous enzymes, including cellulose, hemicellulose, lignin and chitosan [4-5]. Rosa roxburghii $(R S)$ is one of the characteristic fruits in Guizhou Province. Because of its sour and astringent, it is mostly developed into fruit juice, fruit wine and other processing products. With the increase of processing products, a large number of processing by-products are produced [6-8]. As a rich and economic resource, the comprehensive development and utilization of $R S$ pomace can not only improve the utilization value of pomace, extend the industrial chain of pomace processing, but also reduce the environmental pollution [9]. In recent years, many scholars have made many explorations and attempts on the comprehensive utilization of $R S$. In view of the rich dietary fiber in $R S$ dregs, and the low cost of chemical extraction of dietary fiber, which is suitable for industrial production and other characteristics [10], in this study, the processing waste $R S$ pomace were used as raw materials, and the purpose of extracting IDF was achieved by adjusting alkali and acid to remove protein, other sugar, pectin and other impurities in the dregs; the experimental results were dietary fiber. The selection of materials provides experimental basis, and also provides theoretical basis for increasing the added value of $R S$.

\section{Materials and Methods}

The $R S$ residue was collected in the Longli county (Guizhou province, China) in September 2016, which after $R S$ juice was taken to microwave vacuum, drying, and stored at $-20^{\circ} \mathrm{C}$ until it was used for the purpose of experiment.

\subsection{Extraction process of IDF from rosa roxburghii residue}

$R S$ pomace $\rightarrow$ drying and sieving $\rightarrow$ weigh $\rightarrow$ add water to adjust the material liquid ratio $\rightarrow$ alkali treatment (protein decomposition) $\rightarrow$ water bath $\rightarrow$ filter $\rightarrow$ rinse with distilled water $\rightarrow$ acid treatment (decomposition of starch, pectin) $\rightarrow$ water bath $\rightarrow$ rinse $\rightarrow 6000 \mathrm{r} / \mathrm{min}$ centrifugal separation $\rightarrow$ drying $\rightarrow$ crushing $\rightarrow$ IDF.

\subsection{Alkali method}

The dietary fiber was extracted from $R S$ pomace by adding $2.0 \mathrm{~g}$ pomace into water. The effects of different $\mathrm{pH}$ value $(9,10,11,12)$, the material liquid ratio $(1: 5$, $1: 10,1: 15,1: 20,1: 25)$, hydrolysis temperature $(40,50$, $\left.60,70,80^{\circ} \mathrm{C}\right)$ and time $(40,60,80,100,120 \mathrm{~min})$ on the extraction rate of IDF from $R S$ pomace were studied under the same conditions. On the basis of single factor experimental data, $\mathrm{L}_{9}\left(3^{4}\right)$ orthogonal experiment was

a Corresponding author: lizi008009@126.com;

Female, Ph.D., associate professor, mainly engaged in nutrition research. 
carried out, and the optimum alkali process conditions were determined by analyzing the experimental results.

\subsection{Acid method}

Weigh $2.00 \mathrm{~g}$ of $R S$ fruit residue, rinse it with distilled water under the optimal condition of alkali method, the effects of different $\mathrm{pH}$ value $(1,2,3,4,5)$, the material liquid ratio $(1: 5,1: 10,1: 15,1: 20,1: 25)$, hydrolysis temperature $\left(40,50,60,70,80^{\circ} \mathrm{C}\right)$ and time $(60,80,100$, $120,140 \mathrm{~min})$ on the extraction rate of IDF from $R S$ pomace were studied under the same conditions. On the basis of single factor experimental data, $\mathrm{L}_{9}\left(3^{4}\right)$ orthogonal experiment was carried out, and the optimum acid process conditions were determined by analyzing the experimental results.

\subsection{Verification test}

According to the orthogonal experiment of alkali and acid treatment, the best process parameters of extracting IDF from $R S$ were obtained.

\subsection{Yield}

IDF yield(\%)=IDF dry matter quality (g)/ rosa roxburghii pomace dry matter quality $(\mathrm{g}) * 100 \%$

\subsection{Statistical analysis}

Values are expressed as mean +/- standard deviation. Statistical analyses were performed by one-way analysis of variance with the Duncan's multiple range test and correlation of the data (SPSS 24.0, Illinois, USA). P values of less than 0.05 were considered statistically significant.

\section{Results and Discussion}

\subsection{Alkali method}

\subsubsection{Single factor experiments}

As shown in Figure 1(a), with the increase of water bath time, the IDF yield of $R S$ decreased slowly and then increased rapidly. The time of alkali treatment is short, which may be due to the fact that alkali can not completely treat these protein, resulting in low yield; it is significantly higher than other groups at $100 \mathrm{~min}$ $(p<0.05)$; while water bath more than $100 \mathrm{~min}$, the cellulose contained in $R S$ fruit residue is also hydrolyzed by alkali solution, resulting in the gradual decline of IDF yield [11]. In view of this, three levels of orthogonal test were selected as $80 \mathrm{~min}, 100 \mathrm{~min}$ and $120 \mathrm{~min}$.

With the increase of temperature, the IDF yield of $R S$ increased and then decreased. The movement rate of water molecules in the solution increased with the increase of temperature $[9,12]$. At the beginning of the reaction, the protein, fat and other substances in the $R S$

gradually dissolved. The IDF yield reached the highest when the water bath temperature was $50^{\circ} \mathrm{C}(\mathrm{p}<0.05)$; when the temperature was too high and gradually increased, the dietary fibers such as cellulose and hemicellulose depolymerized $[9,12]$, resulting in a downward trend in the yield of IDF. When the temperature is $70{ }^{\circ} \mathrm{C}$, it tends to be stable $(\mathrm{p}>0.05)$, probably because most of hemicellulose and part of cellulose are hydrolyzed [13].

Fig.1(c) shows that the IDF yield of $R S$ increases gradually with the increase of the solid-liquid ratio. When the solid-liquid ratio is low, it may not be able to decompose the protein and other impurities due to the insufficient contact between the alkali liquid and $R S$ when the ratio reaches $1: 15$, the protein and fat in it will be alkaline hydrolyzed by the full contact between the alkali liquid and $R S$ [14], so the IDF yield is the highest $(\mathrm{p}<0.05)$; The continuous increase of solid-liquid ratio will make the raw material of $R S$ absorb water and expand, or be decomposed by alkali solution. At the same time, too much extraction solution is not conducive to the later separation and drying, increasing the process and time consumption [15], resulting in the decline of IDF yield, and gradually tend to be flat. Therefore, 1:10, $1: 15$ and 1:20 were selected as the three levels of orthogonal experiment.

It can be seen from Fig.1(d) that the change of $\mathrm{pH}$ value has a great influence on the yield of IDF from $R S$. With the increase of $\mathrm{pH}$ value, the yield gradually increases $(p>0.05)$. When the $\mathrm{pH}$ value is 12 , the yield of IDF is significantly higher than that of other groups $(p<0.05)$, which may be caused by the full reaction between solution and IDF $[13,16]$.

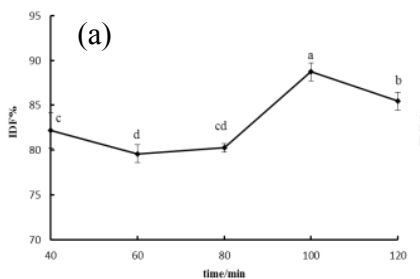

(c)
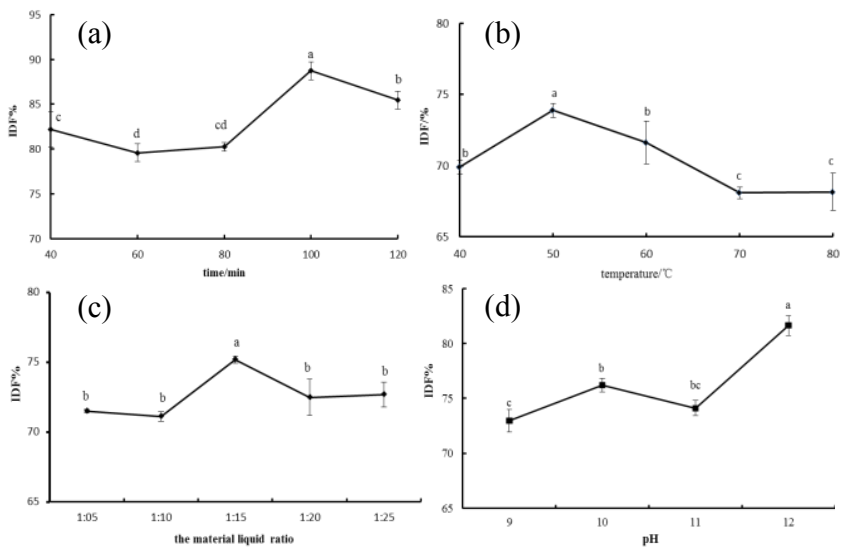

(d)

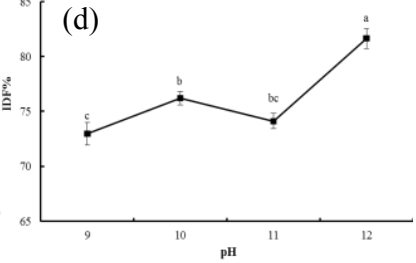

Figure 1 The effect of alkali on the yield of IDF

\subsubsection{Orthogonal experiment}

On the basis of single factor experimental results of alkali treatment, three better levels were determined respectively among the four factors affecting the yield of IDF from $R S$, including alkali bath time, water bath temperature, $\mathrm{pH}$ value and solid-liquid ratio. $\mathrm{L}_{9}\left(3^{4}\right)$ orthogonal table was selected for experimental optimization, according to table 1 , the main and secondary order of influence on the yield of IDF of $R S$ by alkali treatment is alkali extraction time $>$ solid-liquid ratio $>\mathrm{pH}>$ water bath temperature; and the optimum 
technological conditions for extracting IDF from $R S$ pomace by this method were $\mathrm{A}_{1} \mathrm{D}_{3} \mathrm{C}_{3} \mathrm{~B}_{3}$ : adding distilled water to $2.00 \mathrm{~g} R S$ by solid-liquid ratio of $1: 15$, adjusting $\mathrm{pH}$ value of $12,60{ }^{\circ} \mathrm{C}$ constant temperature water bath for $80 \mathrm{~min}$, and adjusting $\mathrm{pH}$ value $3,50{ }^{\circ} \mathrm{C}$ water bath for $60 \mathrm{~min}$ after rinsing. The yield of IDF was $(79.88 \pm 0.2) \%$.

\subsection{Acid method}

\subsubsection{Single factor experiments}

Table 1 Analysis table of orthogonal test results

\begin{tabular}{|c|c|c|c|c|c|}
\hline number & A (time/min) & B (temperature $\left./{ }^{\circ} \mathrm{C}\right)$ & $\begin{array}{c}\mathrm{C} \\
(\mathrm{pH})\end{array}$ & $\begin{array}{c}\text { D } \\
\text { (material liquid ratio) }\end{array}$ & yield $(\%)$ \\
\hline 1 & $1(80)$ & $1(40)$ & $1(10)$ & $1(1: 5)$ & 75.44 \\
\hline 2 & 1 & $2(50)$ & $2(11)$ & $2(1: 10)$ & 76.35 \\
\hline 3 & 1 & $3(60)$ & $3(12)$ & $3(1: 15)$ & 79.88 \\
\hline 4 & $2(100)$ & 1 & 2 & 3 & 75.40 \\
\hline 5 & 2 & 2 & 3 & 1 & 75.50 \\
\hline 6 & 2 & 3 & 1 & 2 & 73.49 \\
\hline 7 & $3(120)$ & 1 & 3 & 2 & 71.12 \\
\hline 8 & 3 & 2 & 1 & 3 & 72.99 \\
\hline 9 & 3 & 3 & 2 & 1 & 73.06 \\
\hline $\mathrm{K}_{1}$ & 231.67 & 221.96 & 221.92 & 224.00 & \\
\hline $\mathrm{K}_{2}$ & 224.39 & 224.84 & 224.74 & 220.96 & \\
\hline $\mathrm{K}_{3}$ & 217.17 & 226.43 & 226.50 & 228.27 & \\
\hline $\mathrm{k}_{1}$ & 77.22 & 73.99 & 73.97 & 74.67 & \\
\hline $\mathrm{k}_{2}$ & 74.80 & 74.95 & 74.91 & 73.65 & \\
\hline $\mathrm{k}_{3}$ & 72.39 & 75.48 & 75.50 & 76.09 & \\
\hline $\mathrm{R}$ & 4.83 & 1.49 & 1.53 & 2.44 & \\
\hline
\end{tabular}

It can be seen from Fig.2(b) that with the increase of acid bath temperature, the yield of IDF of $R S$ increased gradually. In the lower temperature range, the hydrolysis reaction increased gradually with the increase of temperature. The reaction system is more viscous at the lower temperature, and it is not easy to realize the separation of liquid slag $[9,18]$. At $60{ }^{\circ} \mathrm{C}$, the yield is significantly higher than that of other groups $(p<0.05)$. Over $60{ }^{\circ} \mathrm{C}$, the yield of IDF decreased significantly $(p<0.05)$, which may be due to the high temperature, and the structure of some hemicellulose, cellulose and other components in dietary fiber was destroyed $[9,18]$.

As shown in Figure 2(c), the IDF yield of $R S$ fruit dregs increases first and then decreases with the increase reaches the maximum value $(p<0.05)$, which is exactly consistent with the result of alkali treatment. If the solidliquid ratio is too high, the IDF yield will be significantly reduced $(\mathrm{p}<0.05)$. If the acid liquid ratio is too low, the IDF yield will not be fully affected by the raw material, and it is not conducive to the acquisition of IDF.

According to Fig.2(d), when the $\mathrm{pH}$ value of the extraction solution is small, the yield of IDF increases gradually with the increase of the acidity of the solution, of solid-liquid ratio. When the ratio is $1: 15$, the IDF
As shown in Fig.2(a), the effect of increasing acid treatment time on the yield of IDF from $R S$ showed a trend of increasing first and then decreasing. The shorter acid hydrolysis time would be detrimental to the full hydrolysis of the sample, and the yield was the highest at $100 \min (\mathrm{p}<0.05)$. When the acid bath time is more than $100 \mathrm{~min}$, the extraction rate of IDF may be reduced $[13,16,17]$ because some dietary fiber is cracked or hydrolyzed by hydrogenion, which is $4.06 \%$ lower than that of 100 min acid bath. but the larger acidic environment will cause the hydrolysis of cellulose in the fruit residue sample, which is not conducive to the acquisition of IDF; when the $\mathrm{pH}$ value is 2, 3 and 4, the yield of IDF is higher; With the increasing of $\mathrm{pH}$ value, the decreasing of acidity and the slowing down of hydrolysis reaction, the starch in the fruit dregs could not be decomposed by the acid solution $[9,13,17,18]$, resulting in the significant decrease of IDF yield $(\mathrm{p}<0.05)$.
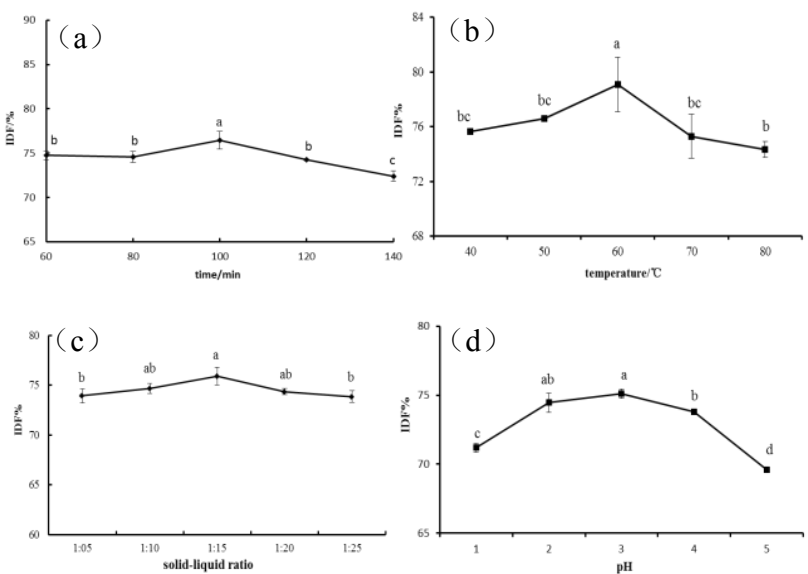

Figure 2 Effect of acid on yield of IDF 


\subsubsection{Orthogonal experiment}

Based on the orthogonal optimal conditions of alkali factors, aiming at the four factors of acid treatment, such as water bath time, $\mathrm{pH}$ value, water bath temperature and solid-liquid ratio, and according to the three optimal levels determined by the single factor experiments of these factors, orthogonal optimization tests are carried out, and $\mathrm{L}_{9}\left(3^{4}\right)$ orthogonal table is selected for the preparation process optimization. According to the analysis of orthogonal experiment results, it can be seen from table 2 that the primary and secondary order of influencing the yield of fruit dregs IDF under the condition of acid action is: water bath temperature $>$ time $>\mathrm{pH}>$ solid-liquid ratio; and the best process condition of extracting fruit dregs IDF by chemical method (acid method) is $\mathrm{A}_{2} \mathrm{~B}_{2} \mathrm{C}_{3} \mathrm{D}_{2}$, that is, adding distilled water to $2.00 \mathrm{~g}$ fruit dregs according to the solid-liquid ratio of $1: 15$, adjusting the $\mathrm{pH}$ value to 12 , $60{ }^{\circ} \mathrm{C}$ constant temperature water bath for $80 \mathrm{~min}$, after rinsing adjust the $\mathrm{pH}$ value to $3,50^{\circ} \mathrm{C}$ water bath for 100 $\min$.

\subsection{Verification test}

According to the results of orthogonal experiments of alkali method and acid method, add distilled water to $2.00 \mathrm{~g} R S$ residue according to the ratio $1: 15$, adjust the $\mathrm{pH}$ value to $12,60^{\circ} \mathrm{C}$ constant water bath for $80 \mathrm{~min}$, rinse to neutral, then adjust the $\mathrm{pH}$ value to $3,50{ }^{\circ} \mathrm{C}$ water bath for $100 \mathrm{~min}$, rinse, centrifugal separation, the yield of IDF was $(86.3 \pm 1.0) \%$ after dry powder extraction, which was higher than the orthogonal experiment results of alkali method (Table 1) and acid method (Table 2), and also higher than the chemical extraction of alfalfa residue IDF [19], carrot residue IDF [20] and bitter almond peel IDF [21].

Table 2. Analysis table of orthogonal test results

\begin{tabular}{cccccc}
\hline $\begin{array}{c}\text { num } \\
\text { ber }\end{array}$ & $\begin{array}{c}\mathrm{A} \\
(\text { temperat } \\
\left.\text { ure/ }{ }^{\circ} \mathrm{C}\right)\end{array}$ & $\begin{array}{c}\mathrm{B} \\
(\mathbf{p H})\end{array}$ & $\begin{array}{c}\mathrm{C} \\
\text { (time } \\
\text { /min) }\end{array}$ & $\begin{array}{c}\text { D } \\
\text { (materia } \\
\text { ratio) }\end{array}$ & yield (\%) \\
\hline 1 & $1(40)$ & $1(2)$ & $1(60)$ & $1(1: 10)$ & 73.04 \\
2 & 1 & $2(3)$ & $2(80)$ & $2(1: 15)$ & 73.83 \\
3 & 1 & $3(4)$ & $3(100)$ & $3(1: 20)$ & 75.45 \\
4 & $2(50)$ & 1 & 2 & 3 & 73.67 \\
5 & 2 & 2 & 3 & 1 & 80.06 \\
6 & 2 & 3 & 1 & 2 & 78.86 \\
7 & $3(60)$ & 1 & 3 & 2 & 75.86 \\
8 & 3 & 2 & 1 & 3 & 77.68 \\
9 & 3 & 3 & 2 & 1 & 74.00 \\
$\mathrm{~K}_{1}$ & 222.32 & 222.57 & 229.58 & 227.10 & \\
$\mathrm{~K}_{2}$ & 232.59 & 231.57 & 221.50 & 228.55 & \\
$\mathrm{~K}_{3}$ & 227.54 & 228.31 & 231.37 & 226.80 & \\
$\mathrm{k}_{1}$ & 74.11 & 74.19 & 76.53 & 75.70 & \\
$\mathrm{k}_{2}$ & 77.53 & 77.19 & 73.83 & 76.18 & \\
\hline & & & & & \\
\hline
\end{tabular}

\begin{tabular}{lllll}
\hline $\mathrm{k}_{3}$ & 75.85 & 76.10 & 77.12 & 75.60 \\
$\mathrm{R}$ & 3.42 & 3.00 & 3.29 & 0.58 \\
\hline
\end{tabular}

\section{Conclusion}

Since the 20th century, the proportion of dietary fiber in the dietary structure has been increasing. In this paper, the IDF in the raw material of $R S$ was extracted by chemical method. The preparation process was optimized by single factor and orthogonal experiment, such as alkali method to remove protein, acid method to remove starch, pectin, etc. The yield of IDF was $(86.3 \pm 1.0) \%$ after washing, centrifuging and drying. The optimized extraction process of dietary fiber can not only increase the added value of $R S$ products in Guizhou province, but also avoid the waste of characteristic fruit resources, play a positive role in environmental protection, and lay a solid theoretical foundation for the comprehensive utilization and development of $R S$.

\section{Acknowledgements}

This research was financially supported by the Key Laboratory of functional food Project of Education Department of Guizhou Province (China) (Project KY[2016]007), innovation and entrepreneurship training program for college students (20195200355), the special funding of Guiyang science and technology bureau and Guiyang University [GYU-KYZ(2019 2020)PT11-04] for financial support.

\section{References}

1. D.A. Kieffer, R.J. Martin, S.H. Adams, Advances in Nutrition, 7, 6 (2016)

2. V. Suryanti, T. Kusumaningsih, Y.S. Rumingtyas, IOP Conference Series: Materials Science and Engineering 193(2017)

3. M. Birgitte, H. Kristi, M. Ingrid, Plos One, 11, 5(2016)

4. Elif. Karaman, E. Yılmaz, N. B. Tuncel, Bioactive Carbohydrates and Dietary Fibre, 11(2017)

5. F. Xie, Y. Wang, J. Wu, Starch/Stärke, 68(2016)

6. D. Li, N. Jiang, Agricultural products processing, 2 (2016)

7. Y.Q. Liu, Y.L. Sun, M. Lu, Journal of nutrition, 37, 3(2015)

8. J.W. Xu, S.K. Vidyarthi, W.B. Bai, Z.L. Pan, J. Functional Foods, 60(2019)

9. L.X. Jia, C.Q. Hu, G. Li, Guizhou agricultural sciences, 36, 2 (2008)

10. Y.M. Liu, Central South University of forestry science and technology, 9, (2013)

11. P.L. Shao, M. Xu, Agricultural science research, 24, (2003)

12. S. Cao, X. Huang, T.X. Deng, Light industry technology, 4, (2018) 
13. J.X. Guo, Y. Wu, L. Xu, Journal of Xinjiang Agricultural University, 32, 6 (2009)

14. H. Deng, J.R. Song, H.B. Shi, Food and fermentation industry, 28, 5 (2002)

15. J. Sun, F.X. Niu, R.X. Yue, Journal of Nuclear Agriculture, 28, 7 (2014)

16. R.Z. Song, X.L. Wei, X.C. Li, Food research and development, 38, 24 (2017)

17. W.T. Zhu, S.J. Wu, W.T. Yang, food industry, 12, (2017)

18. X.C. Liang, M.L. Shi, Guangdong chemical industry, 44, 12 (2017)

19. C.M. Feng, Z.Z. Cao, Journal of Gansu Agricultural University, 42, 1 (2007)

20. H.X. Shan, Food and fermentation technology, 45, 4 (2009)

21. H. Shen, X.H. Fan, Q.A. Zhang, Y.M. Li, Food Sci. $35,20(2014)$ 